\title{
The Value of Cardiac Troponins in Diagnosis and Differential Diagnosis of Pulmonary Embolism
}

\author{
Nalan Demir ${ }^{1 *}$, Numan Ekim² ${ }^{2}$ I.Kivilcim Oguzulgen ${ }^{2}$, and Neslihan Bukan ${ }^{3}$ \\ ${ }^{1}$ Ankara University School of Medicine Department of Chest Disease, Ankara, Turkey \\ ${ }^{2}$ Gazi University School of Medicine Department of Chest Disease, Ankara, Turkey \\ ${ }^{3}$ Gazi University School of Medicine Department of Biochemistry, Ankara, Turkey
}

\section{Abstract}

Aim: Pulmonary Embolism (PE) is a major cause of deaths in hospitals. Early diagnosis and emergent treatment decrease mortality rate. Cardiac troponins are thought to be useful in early diagnosis and especially in predicting PE prognosis. The aims of this study are 1) to investigate the diagnostic importance of cardiac troponins in PE and 2) to evaluate the relationship between disease severity, right ventricular dilatation and high levels of cardiac troponins. This study also aims to determine the role of cardiac troponins in differential diagnosis of PE from other pulmonary diseases that may also cause hypoxemia.

Methods: A total number of 117 patients, 59 of whom, diagnosed with PE (group I) and 58 with asthma attack and community acquired pneumonia (group II) were enrolled in the study. Cardiac troponin T (cTnT) and I (cTnl) levels were measured twice in all patients during inclusion and within 12 hours. Clinical and laboratory findings were recorded.

Results: cTnT and cTnl were positive in $8(13.6 \%)$ and $48(81.3 \%)$ patients in group I and in $1(1.7 \%)$ and $47(81.3 \%)$ patients in group II (1.72\%), respectively ( $p=0.03$ and 1.7$)$. Mean $c T n l$ levels were $3.92 \pm 2.65 \mathrm{ng} / \mathrm{ml}$ in group I and $3.30 \pm 2.93 \mathrm{ng} / \mathrm{ml}$ in group II $(\mathrm{p}>0.05)$. In existence of hpoxemia $\left(\mathrm{PaO}_{2} \leq 55 \mathrm{mmHg}\right)$, there was no correlation between groups and cTnT and cTnl levels. Cardiac troponin levels were more positive in patients who had echocardiographic pathology due to pulmonary embolism. cTnT and cTnl elevation was not found to be related with the clinical severity of PE, however massive PE cases had high troponin levels. The sensitivity, specificity, PPV and NPV of cTnl (cut-off value $2.935 \mathrm{ng} / \mathrm{ml}$ ) and cTnT positivity $(>0.01 \mathrm{ng} / \mathrm{ml}$ ) were found as $66.1 \%, 60.3 \%, 62.9 \%, 63.6 \%$, and $13.6 \%, 98.3 \%, 88.9 \%$, and $52.8 \%$, respectively. Troponin I was a differential factor for patients with pulmonary embolism when it was compared with controls, although it was no very sensitive. Mortality rate was $7.4 \%$ and high levels of cTnl positivity ( $\geq 3 \mathrm{ng} / \mathrm{ml}$ ) were detected in these cases in present study.

Conclusion: Cardiac troponins might be a role in differential diagnosis for PE, but we should be kept in mind that they could be elevated in pneumonia and asthma attack. Another result of this study suggests that cardiac troponins might be useful parameter for detection of right ventricular dysfunction, prediction of mortality and massive disease in PE patients.

Keywords: Cardiac troponins; Pulmonary embolism

Abbreviations: PE: Pulmonary Embolism; CAP: Community Acquired Pneumonia; COPD: Chronic Obstructive Pulmonary Diseases; CPK: Creatine Phospho Kinase; CK-MB: Creatine Kinaseisoenzyme MB; cTnT: Cardiac Troponin T; cTnI: Cardiac Troponin I; ABG: Arterial Blood Gas; ECG: Electrocardiogram; ECHO: Echocardiography; RV: Right Ventricle; LV: Left Ventricle; Thorax CT: Thorax Computed Tomography

\section{Introduction}

Pulmonary Embolism (PE) is an important clinical problem with an incidence of 21-69/100000 [1]. PE was reported as the cause of $10 \%$ of the hospital deaths in both medical and surgical in-patients. While mortality rate is $30 \%$ in untreated patients, this rate decreases to $3 \%$ with appropriate treatment. Considering the mortality rates, $\mathrm{PE}$ should be diagnosed immediately and for the cases that necessitate, the decision of thrombolytic treatment should be made as early as possible $[2,3]$.

Right ventricular function is an important prognostic factor in PE. Results of previous studies showed that right ventricular dysfunction is associated with poor prognosis and high mortality rates [4]. As a result of pulmonary arterial obstruction and increase in pulmonary vascular resistance, right ventricular after load increases and acute right ventricular dilatation develops with increase of right ventricular pressure up to pathological levels. In addition, myocardial damage and ischemia might occur in some cases $[2,5,6]$.
Cardiac troponins are biochemical markers that are highly sensitive to myocardial cell damage. They have been very helpful in diagnosis and prognosis of acute coronary syndrome. Since 1939 myocardial ischemia and damage were reported in acute PE without prominent coronary artery disease, recently several studies showed that cardiac troponins might increase in PE [5-13].

The primary outcomes of this study are to investigate the diagnostic importance of cardiac troponins in $\mathrm{PE}$ and to determine the role of cardiac troponins in differential diagnosis of PE from other pulmonary diseases (e.g. pneumonia and asthma attack) that may cause hypoxemia and be clinically confused with PE. As secondary outcomes, this study also aims to evaluate 1) the relationship between levels of cardiac troponins and disease severity, and 2) the relationship between levels of cardiac troponins and right ventricular dysfunction.

*Corresponding author: Nalan Demir, Department of Pulmonary Medicine Ankara University School of Medicine, 06100 Cebeci/Ankara, Turkey, Tel: +90312-5957077; Fax: +90-312-3190046; E-mail: dr.ndemir@gmail.com

Received October 18, 2012; Accepted December 26, 2012; Published December 28, 2012

Citation: Demir N, Ekim N, Oguzulgen IK, Bukan N (2012) The Value of Cardiac Troponins in Diagnosis and Differential Diagnosis of Pulmonary Embolism. Pulmon Resp Med 2:134. doi:10.4172/2161-105X.1000134

Copyright: ( 2012 Demir N, et al. This is an open-access article distributed unde the terms of the Creative Commons Attribution License, which permits unrestricted use, distribution, and reproduction in any medium, provided the original author and source are credited. 


\section{Material and Methods}

\section{Study subjects}

A total number of 117 patients, diagnosed with acute PE $(n=59)$, Community Acquired Pneumonia (CAP) $(n=31)$ and asthma attack $(n=27)$ were included in the study. PE was confirmed by highprobability ventilation-perfusion lung scanning (according to PIOPED criteria) or spiral computed thorax tomography [14-17]. The diagnosis of CAP was established according to the IDSA Guideline. An acute infection of the pulmonary parenchyma that was associated with some symptoms of acute pulmonary infection, accompanied by the presence of an acute infiltration on a chest radiograph or auscultatory findings consistent with CAP was defined as CAP [18].

Asthma diagnosis was made according to the Global Initiative for Asthma (GINA) recommendations [19].

\section{Study design}

Fifty-nine patients diagnosed with acute PE were study group (Group 1) and 58 patients diagnosed with pneumonia and asthma attack were evaluated as control group (Group II). Patients with pathology that may cause high levels of cardiac troponins (acute myocardial infection, congestive heart failure, sepsis, renal failure, drug toxicity, cerebrovascular events, ultra-exercise, hypothyroidism, COPD, primary pulmonary hypertension) were not included in the study [20,21]. Additionally, five cases (3 pulmonary embolism and 2 pneumonia) admitted to our clinic were excluded due to unavailable cardiac troponin values.

For all patients, symptoms, symptom durations, physical examination findings, predisposing factors for PE and risk factors (smoking, hypercholesterolemia, systemic hypertension, diabetes mellitus, and atherosclerosis story in family) for coronary artery disease were recorded at admission.

Severity of clinical presentation in patients with PE was divided into 3 groups according to Goldhaber: 1. Massive PE: cases with persistent systemic hypotension (systolic blood pressure $<100 \mathrm{mmHg}$ ), cardiogenic shock and right ventricular dysfunction 2. Submassive PE: cases with right ventricular dysfunction but normal blood pressure 3 . Small PE: cases without right ventricular dysfunction and hypotension $[22,23]$.

\section{Laboratory analyses}

On admission; all the patients had physical examination, complete blood count, routine biochemical analysis, chest X-ray, Arterial Blood Gas Analysis (ABG), D-dimer level and ECG pathologies were recorded (sinusoidal tachycardia, incomplete and complete right branch block, right axis deviation, non-specific ST variations, atrial fibrillation and atrial flutter).

Transthoracic Echocardiography (ECHO) was applied to 40 of 59 patients with PE. End-diastolic diameter of Right Ventricle (RV), Left Ventricle (LV) and RV/LV ratio, presence of tricuspid failure, pulmonary arterial pressure level, right ventricular dilatation or hypokinesis, paradoxical septal movement and thrombus in right heart cavities were evaluated.

Right ventricular dysfunction was evaluated as positive in the presence of at least one of the following signs [2,24]:

1. Presence of right ventricular dilatation (End diastolic diameter of right ventricle $\geq 30 \mathrm{~mm}$ or end diastolic $\mathrm{RV} / \mathrm{LV}$ diameter ratio $\geq 1$ )

\section{Paradoxical septal movement}

3. Right ventricular hypokinesis

4. Tricuspid failure (Jet velocity $\geq 2.5 \mathrm{~m} / \mathrm{min}$.)

$\mathrm{CPK}, \mathrm{CK}-\mathrm{MB}$ and cTnT levels were measured twice in all patients, first on admission and then in the first 12 hours. For cTnT, levels of 0.01 $\mathrm{ng} / \mathrm{ml}$ or above were accepted as positive. Venous blood samples were collected for $\mathrm{cTnI}$ (first on admission and then in the first 12 hours) and centrifuged at $3000 \mathrm{rpm}$ for 15 minutes and saved at $-80^{\circ} \mathrm{C}$. All samples were analyzed with cTnI ELISA test (solid phase enzymelinked immunosorbent assay) (specificity: $87.5 \%$, sensitivity: \%100, CI: 95\%). Values above $1.0 \mathrm{ng} / \mathrm{ml}$ were evaluated as positive [25].

\section{Statistical analysis}

Data were analyzed by using SPSS for Windows release 10.0.1 (SPSS, Chicago, IL). Values were expressed as mean \pm SD. The chisquare test was used to compare categorical variables. T-test was used to compare the mean differences in independent samples. In addition, case summary reports and frequency charts were used to analyze the group variables. All $p$ values were two-tailed and a $p$ value $<0.05$ was considered statistically significant. ROC analysis was performed for cTnI in addition to screen tests.

\section{Results}

Seventy-five female and 42 male, totally 117 patients were enrolled in the study. Comparative demographic data of the patients are shown in Table 1. At least one risk factor was present in $93.2 \%$ (55 cases) of the patients with PE.

Patients with PE were evaluated as group I and patients with asthma attack and pneumonia as group II. When the symptoms were compared in two groups, pleuritic type chest pain was higher in group I. Presence of dyspnea, palpitation and hemoptysis, were not different between groups. Syncope, pre-syncope and cyanosis were only present in group I (PE patients), at a ratio of $16.9 \%$ (n: 10$), 11.9 \%$ (n: 7) and $5.1 \%$ (n: $3)$ respectively $(\mathrm{p}<0.05)$. Cough, phlegm and fever were significantly higher in group II $(\mathrm{p}<0.05)$ (Table 2$)$. Vital signs and laboratory findings of subjects and controls were shown in Table 3 . When two groups were compared for ECG pathology, significantly higher rate

\begin{tabular}{|l|c|c|c|c|}
\hline & PE $(n=59)$ & $\begin{array}{c}\text { Pneumonia } \\
(n=31)\end{array}$ & $\begin{array}{c}\text { Asthma attack } \\
(n=27)\end{array}$ & $p$ value \\
\hline Female/Male & $40 / 19$ & $14 / 17$ & $21 / 6$ & 0.24 \\
\hline Age (years) & $57.17 \pm 17.34$ & $52.65 \pm 21.59$ & $53.15 \pm 14.67$ & 0.44 \\
\hline Symptom duration (days) & $5.03 \pm 5.84$ & $6.0 \pm 4.65$ & $11.63 \pm 11.50$ & 0.001 \\
\hline Smoking (pack-year) & $30.12 \pm 18.19$ & $35.23 \pm 26.07$ & $22 \pm 12.74$ & 0.30 \\
\hline
\end{tabular}

Table 1: General properties of patients and control groups.

\begin{tabular}{|l|c|c|c|}
\hline & $\begin{array}{c}\text { Group I (n=59) } \\
\text { N of patients (\%) }\end{array}$ & $\begin{array}{c}\text { Group II (n=58) } \\
\text { N of patients (\%) }\end{array}$ & p \\
\hline Chest pain* $^{*}$ & $39(66.1)$ & $19(32.8)$ & 0.001 \\
\hline Shortness of breath & $49(83.1)$ & $40(69)$ & 0.86 \\
\hline Syncope* & $10(16.9)$ & 0 & 0.01 \\
\hline Presyncope* $^{*}$ & $7(11.9)$ & 0 & 0.01 \\
\hline Hemoptysis & $6(10.2)$ & $1(1.7)$ & 0.11 \\
\hline Palpitation & $8(13.6)$ & $2(3.4)$ & 0.94 \\
\hline Cough* & $19(32.2)$ & $33(56.9)$ & 0.01 \\
\hline Phlegm $^{*}$ & $9(15.3)$ & $19(32.8)$ & 0.03 \\
\hline Fever & $12(20.3)$ & $24(41.4)$ & 0.01 \\
\hline Cyanosis & $3(5.1)$ & 0 & 0.24 \\
\hline
\end{tabular}

Table 2: Frequencies of symptoms in group I and II ( $\left.{ }^{*} p<0.05\right)$. 


\begin{tabular}{|l|c|c|}
\hline & $\begin{array}{c}\text { Group I } \\
(\mathbf{n = 5 9 )}\end{array}$ & $\begin{array}{c}\text { Group II } \\
(\mathbf{n = 5 8})\end{array}$ \\
\hline Pulse/min. & $96(64-130)$ & $98(53-140)$ \\
\hline Respiratory rate/min. & $24(18-36)$ & $24(16-40)$ \\
\hline Systolic blood pressure $(\mathrm{mmHg})$ & $120(90-180)$ & $120(70-170)$ \\
\hline Diastolic blood pressure $(\mathrm{mmHg})$ & $75(60-100)$ & $80(40-120)$ \\
\hline Fever $\left({ }^{\circ} \mathrm{C}\right)$ & $36.8(36.0-40.0)$ & $36.7(36.0-38.7)$ \\
\hline Leucocytes/mm & & $11.3(3.9-27.8)$ \\
\hline $\mathrm{LDH}^{3}$ & $9.7(2.5-28.5)$ & $192(123-460)$ \\
\hline $\mathrm{SaO}_{2} \%$ & $190(106-577)$ & $92.4(62.0-98.1)$ \\
\hline
\end{tabular}

Continuous variables expressed as median (minimum and maximum values between brackets)

Table 3: The physical examination and laboratory findings of subjects and controls.

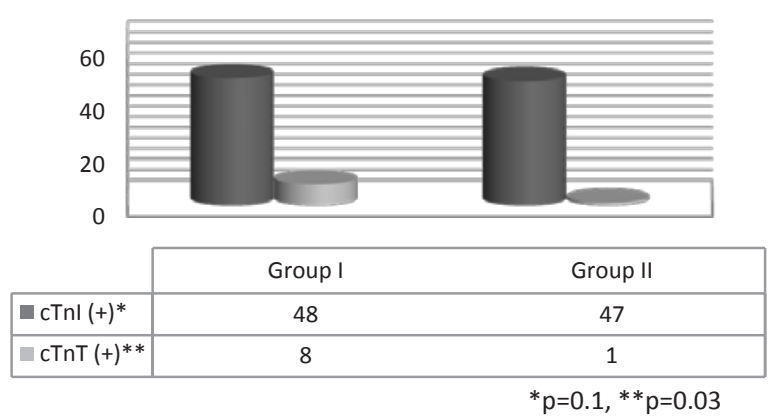

Figure 1: The rates of positivity of cTnl and cTnT in group I and II.

of pathologic findings were observed in group I compared to group II (Pathologic ECG finding rates of group I and group II were 59.3\% and $37.9 \%$, respectively) $(\mathrm{p}=0.02)$.

CPK and CK-MB were positive in 7 patients in group I (11.9\%) and 5 patients in group II $(8.6 \%)(\mathrm{p}>0.05)$. These high levels returned to normal in their follow-up.

Positivity of cTnT was detected in 8 patients of PE group (13.6\%) and it also returned to the normal in the follow-up measurements. It was positive in one case in group II (1.72\%) This result was significant, statistically $(\mathrm{p}=0.03)$.

Because of positivity of $\mathrm{cTnI} \geq 1.0 \mathrm{ng} / \mathrm{ml}$ was observed in most $\mathrm{PE}$ patients, we accepted as cTnI levels were positive above $1.5 \mathrm{ng} / \mathrm{dl}$ and it was detected in 48 patients of PE group $(81.35 \%)$ and it also returned to the normal in the follow-up measurements. It was positive in 47 cases in group II (81.3\%). There was no difference between group I and II according to the positivity of cTnI. When we evaluated to mean cTnI levels in both groups, it was $3.92 \pm 2.65 \mathrm{ng} / \mathrm{ml}$ in group I and $3.30 \pm$ $2.93 \mathrm{ng} / \mathrm{ml}$ in group II. Although the levels were slightly higher in PE group compared to group II, this difference was not significant $(\mathrm{p}=0.23)$ (Figure 1).

Arterial blood gas analysis was similar between group I and II (Table 4). In order to investigate the relation between the severity of hypoxemia and cardiac troponin levels, the subjects were grouped according to presence of hypoxemia $\left(\mathrm{PaO}_{2}>55 \mathrm{mmHg}, \mathrm{n}=73\right.$ vs. $\leq 55$ $\mathrm{mmHg}, \mathrm{n}=43$ ) However, mean cTnI levels and positivity of cTnT were not different between groups (mean cTnI levels were $3.97 \pm 3.26$ vs. $3.40 \pm 2.49 \mathrm{ng} / \mathrm{ml}, \mathrm{p}=0.32$ and positivity of cTnT was observed in $4 v s .5$ cases respectively, $\mathrm{p}=0.72$ ).

Pathological findings were detected in thirty-one of the $40 \mathrm{PE}$ patients who underwent echocardiography. In patients with pathological ECHO findings, mean cTnI level was $4.77 \pm 3.11 \mathrm{ng} / \mathrm{ml}$, whereas in patients with normal findings they were $2.45 \pm 0.88 \mathrm{ng} / \mathrm{ml}$ ( $\mathrm{p}=0.03$ ). In 7 of 31 patients who had pathologic findings on ECHO were detected cTnT positivity, but in patients who performed echocardiography, 33 cases had normal TnT levels $(\mathrm{p}=0.17)$. RV dilatation, increased pulmonary arterial pressure and tricuspid regurgitation were more common in the group with $\mathrm{PaO}_{2}<55 \mathrm{mmHg}(\mathrm{p}<0.05)$

According to Goldhabers' severity of clinical presentation; 7 (11.9\%) subjects had massive, $43(72.9 \%)$ had submassive and $9(15.3 \%)$ had small PE (41). Mean cTnI levels were $5.15 \pm 3.63 \mathrm{ng} / \mathrm{ml}, 4.01 \pm 2.64$, and $2.53 \pm 1.08$ in these three groups respectively $(\mathrm{p}=0.13)$. cTnI was positive in all of the patients with massive PE. $c$ TnT levels were positive in 4 and 4 cases with massive and submassive PE. In small PE patients, all cTnT levels were normal ( $\mathrm{p}=0.005)$ (Figure 2).

As high rates of cTnI positivity were detected in both groups, data were re-evaluated with cTnI cut-off value of $2.935 \mathrm{ng} / \mathrm{ml}$ and above. Levels of $1.5 \mathrm{ng} / \mathrm{ml}$ and above were present in $81.35 \%$ (48 subjects) of group I and $81.03 \%$ (47 subjects) of group II. However, levels of 2.935 $\mathrm{ng} / \mathrm{ml}$ and above were present in $66.1 \%$ (39 subjects) of group I and $39.7 \%$ (23 subjects) of group II.

In this study, when threshold was set to $1.5 \mathrm{ng} / \mathrm{ml}$, sensitivity and specificity of cTnI were $81.35 \%$ and $18.96 \%$. Nonetheless, cut-off value of cTnI was found as $2.935 \mathrm{ng} / \mathrm{ml}$, when it compared between subjects and controls. When the threshold was accepted as $2.935 \mathrm{ng} / \mathrm{ml}$, sensitivity, specificity, positive predictive value (PPV) and Negative Predictive Value (NPV) were $66.1 \%, 60.3 \%, 62.9 \%$, and $63.6 \%$, respectively (Table 5). Troponin I was a differential factor for patients with pulmonary embolism when it was compared with controls, although it was no very sensitive $(\mathrm{AUC}=0.612, \mathrm{p}=0.037$ ). The sensitivity, specificity, PPV

\begin{tabular}{|l|c|c|c|}
\hline & Group I & Group II & $p$ \\
\hline $\mathrm{pH}$ & $7.43 \pm 5.31$ & $7.43 \pm 3.90$ & 0.57 \\
\hline $\mathrm{PaO}_{2}{ }^{*}$ & $60.33 \pm 12.54$ & $59.93 \pm 10.69$ & 0.85 \\
\hline $\mathrm{PaCO}_{2}{ }^{* *}$ & $30.88 \pm 5.58$ & $32.79 \pm 4.76$ & 0.05 \\
\hline $\mathrm{HCO}_{3}$ & $21.43 \pm 3.37$ & $21.59 \pm 2.42$ & 0.76 \\
\hline $\mathrm{O}_{2}$ saturation & $89.82 \pm 8.20$ & $91.40 \pm 4.44$ & 0.20 \\
\hline
\end{tabular}

ABG: Arterial blood gas analysis, ${ }^{*} \mathrm{PaO}_{2}$ : Partial oxygen pressure $(\mathrm{mmHg})$ ${ }^{* *} \mathrm{PaCO}_{2}$ : Partial carbondioxide pressure $(\mathrm{mmHg})$

Table 4: Comparison of ABG values between Group I and II.

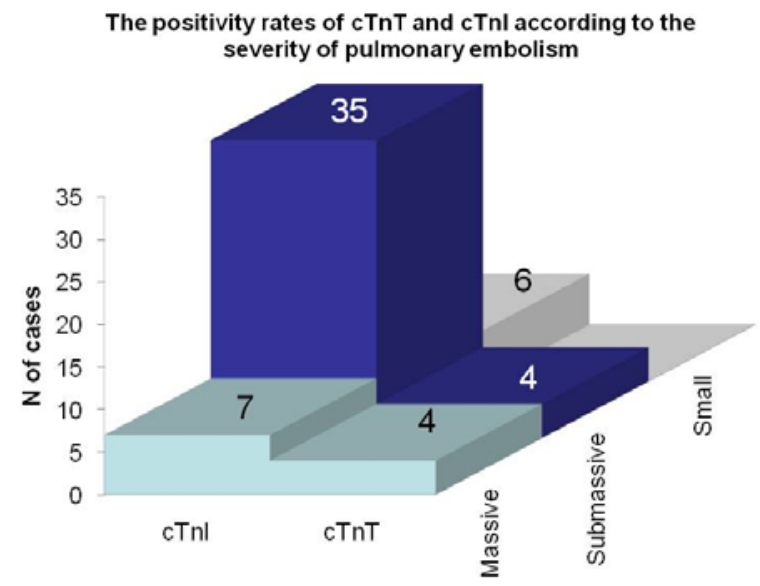

The positivity of cTnT and cTnl

Figure 2: Levels of cTnl and cTnT according to clinical severity of PE. 


\begin{tabular}{|c|c|c|c|c|c|c|c|}
\hline & \multicolumn{2}{|c|}{$\begin{array}{c}\log (\mathrm{cTnl}) \\
(95 \% \mathrm{Cl})\end{array}$} & \multirow[t]{2}{*}{$\begin{array}{l}\text { Specificity } \\
(95 \% \mathrm{Cl})\end{array}$} & \multirow[t]{2}{*}{$\begin{array}{l}\text { Sensitivity } \\
(95 \% \mathrm{Cl})\end{array}$} & \multirow[t]{2}{*}{$\begin{array}{c}\text { PPV } \\
(95 \% \mathrm{Cl})\end{array}$} & \multirow[t]{2}{*}{$\begin{array}{c}\text { NPV } \\
(95 \% \mathrm{Cl})\end{array}$} & \multirow[t]{2}{*}{$\mathrm{p}$} \\
\hline & $(-)(+)$ & & & & & & \\
\hline Group I (PTE) & $20(33.9 \%)$ & $39(66.1 \%)$ & \multirow{3}{*}{$\begin{array}{c}0.603 \\
(0.475-0.719)\end{array}$} & \multirow{3}{*}{$\begin{array}{c}0.661 \\
(0.534-0.769)\end{array}$} & \multirow{3}{*}{$\begin{array}{c}0.629 \\
(0.534-0.715)\end{array}$} & \multirow{3}{*}{$\begin{array}{c}0.636 \\
(0.542-0.722)\end{array}$} & 0.004 \\
\hline Group II (controls) & $35(60.3 \%)$ & $23(39.7 \%)$ & & & & & \\
\hline Total & $55(47.0 \%)$ & $62(53.0 \%)$ & & & & & \\
\hline
\end{tabular}

Table 5: Specificity, sensitivity, PPV and NPV of cTnl for subjects and controls.

\begin{tabular}{|c|c|c|c|c|c|c|c|}
\hline & \multicolumn{2}{|c|}{$\log (\mathrm{cTnT})(95 \% \mathrm{Cl})$} & \multirow{2}{*}{$\begin{array}{l}\text { Specificity } \\
(95 \% \text { Cl) }\end{array}$} & \multirow{2}{*}{$\begin{array}{l}\text { Sensitivity } \\
(95 \% \mathrm{Cl})\end{array}$} & \multirow{2}{*}{$\begin{array}{c}\text { PPV } \\
(95 \% \mathrm{Cl})\end{array}$} & \multirow{2}{*}{$\begin{array}{c}\text { NPV } \\
(95 \% \mathrm{Cl})\end{array}$} & \multirow[t]{2}{*}{$\mathrm{p}$} \\
\hline & $(-)$ & $(+)$ & & & & & \\
\hline Group I (PTE) & $51(86.4 \%)$ & $8(13.6 \%)$ & \multirow{3}{*}{$\begin{array}{c}0.983 \\
(0.909-0.997)\end{array}$} & \multirow{3}{*}{$\begin{array}{c}0.136 \\
(0.07-0.245)\end{array}$} & \multirow{3}{*}{$\begin{array}{c}0.889 \\
(0.814-0.934)\end{array}$} & \multirow{3}{*}{$\begin{array}{c}0.528 \\
(0.814-0.937)\end{array}$} & 0.032 \\
\hline Group II (controls) & $57(98.3 \%)$ & $1(1.7 \%)$ & & & & & \\
\hline Total & $108(92.3 \%)$ & $9(7.7 \%)$ & & & & & \\
\hline
\end{tabular}

Table 6: Specificity, sensitivity, PPV and NPV of cTnT for subjects and controls.

and NPV of cTnT were calculated as $13.6 \%, 98.3 \%, 88.9 \%$, and $52.8 \%$, respectively (with a cut-off value of $0.01 \mathrm{ng} / \mathrm{ml}$ ) (Table 6). At the end of this result, cTnI was more predictive factor for pulmonary embolism. However, when we evaluated the relation of cTnI and cTnT for each groups, there was no statistically significance between subjects and controls ( $\mathrm{p}=1.00$ and $\mathrm{p}=0.245$, respectively).

Four patients with PE progressed fatally. These four subjects had cTnI levels higher than $3 \mathrm{ng} / \mathrm{ml}$. In these cases only one had positive cTnT. Two of them received thrombolytic therapy where the other two only had heparin treatment due to presence of contraindications for thrombolytic therapy.

\section{Discussion}

This study showed that high levels of cardiac troponin could be observed in $\mathrm{PE}$ in the presence of right ventricular dysfunction findings in ECHO. cTnI is known as more sensitive to myocardial damage. In accordance with previous studies, cTnI levels were found to be more positive in PE compared to cTnT in our study, too $[2,20,26,27]$.

When PE group was compared to control group (asthma attack and pneumonia), no relation was observed between cardiac troponin levels and patients' smoking severity, underlying risk factors, physical examination, and lung graphy findings.

In $11.9 \%$ and $8.6 \%$ of the subjects, CPK and CK-MB levels were found to be high for PE and pneumonia and asthma cases. This was no correlated with the results of previous studies suggested that high levels of CK-MB could be observed in PE [28]. Although cTnT levels were more positive in $\mathrm{PE}$ group than cases with pneumonia and asthma attack according to the cTnI positivity, mean cTnI levels were slightly higher in PE patients. This result showed that cardiac troponins might be a role in differential diagnosis for PE, but we should be kept in mind that they could be elevated in other pulmonary diseases such as pneumonia and asthma attack. There was no observed a study which is evaluated cardiac troponins for three diseases (PE, CAP and asthma attack) in literature. In this issue further studies are required.

Kucher et al. [29] observed that QR and ST elevations in V1 in ECG were more common in cTnI positive patients with PE, and they suggested a relation with early mortality [29]. In our study, no significant relation was found between ECG results and troponin levels.

As emphasized in previous studies, cardiac troponins could be more positive in PE patients who developed right ventricular dysfunction $[5,6,13,30,31]$. Likewise, in our study $c \operatorname{TnI}$ and $c \operatorname{TnT}$ levels were high in patients with pathological findings on echocardiography and right ventricular dysfunction.

When cardiac troponin levels and $\mathrm{PaO}_{2}$ levels were compared, no significant relation was detected between $\mathrm{PaO}_{2}$ levels and $c \mathrm{TnI}$ and cTnT. Considering the presence of similar results in asthma attack and pneumonia group and higher rates of positive cTnI levels with increasing degree of hypoxemia, one may think that hypoxemia may cause higher cardiac troponin levels as a result of myocardial ischemia. In addition, with increasing degree of hypoxemia, RV dysfunction was more commonly observed in this study. A few studies were confirmed that cardiac troponins elevated in patients with pneumonia, whereas there is no report for the association of cardiac troponins and asthma attack to date $[32,33]$. However, further studies are needed to clarify this issue.

Although the degree of precision is high for cardiac troponins; it is suggested that a clinician should determine the cut-off values based on measurement techniques that are used in her/his hospital laboratory and this approach should be used in acute PE as in acute coronary syndrome [3]. In our study, since cTnI levels were higher than $1 \mathrm{ng} /$ $\mathrm{ml}$ in most of the cases, it can be concluded that cut-off value should be increased. Although when cTnI levels that are higher than $1.5 \mathrm{ng} /$ $\mathrm{ml}$ and $3 \mathrm{ng} / \mathrm{ml}$ are accepted as positive cTnI levels were higher than 3 $\mathrm{ng} / \mathrm{ml}$ in all of the massive PE patients and no variation was detected in previous data (for $1 \mathrm{ng} / \mathrm{ml}$ and above) when PE group compared to controls.

The presence of any possible contribution of cardiac troponins to prognosis of PE is an important point. Previous studies that focused on this topic note that, morbidity and mortality were higher in the subjects with higher troponin levels [5,34]. This suggests that cardiac troponins might be useful in detection of prognosis. Considering that the mortality rate from PE is very high during the first hour, cardiac troponins might also have an important role for early mortality prediction. Konstantinides et al. showed that cardiac troponins are related with recurrent PE [35]. Since the patients in our study were not followed-up for long time, recurrence rates were not evaluated.

One of the most important causes of death in hospital is still PE. It was reported that progressive, irreversible, right ventricular failure increases mortality $[36,37]$. Similar with the previous studies, mortality rate was $7.4 \%$ and high levels of $c T n I$ positivity $(\geq 3 \mathrm{ng} / \mathrm{ml}$ ) were detected in all cases in the study [38].

Cardiac troponins might help to clinician in estimation of mortality 
risk during early periods of patients, who have poor clinical view with hypertension and severe right ventricular dysfunction.

Limitation of our study is the inability to eliminate subclinical coronary artery disease accompanied with PE. Several views are inline with the findings of subclinical coronary artery disease accompanied with PE. Even considering this, acute developed shortness of breath, chest pain, accompanying hypoxemia, hypocapnia and other clinical and laboratory findings could not be explained with acute coronary syndrome, but further imaging techniques are needed to determine underlying coronary artery disease.

Result of previous studies note that when clinical suspicion/doubt is low, cardiac troponins as in the D-dimer test could not be used to eliminate PE without diagnostic imaging techniques [39-42]. Even though high levels of cardiac troponin could not be used for diagnosis of PE, in the absence of acute coronary syndrome, they can help the clinician to think the possibility of PE presence and to apply necessary imaging techniques and early treatment.

As a conclusion of this study, although cTnT was more positive in PE group than cases with pneumonia and asthma according to the $\mathrm{cTnI}$ positivity, mean cTnI levels were slightly higher in PE patients. Cardiac troponins might be a role in differential diagnosis for PE, but we should be kept in mind that they could be elevated in pneumonia and asthma attack. There were no relationship could be established between severity of PE and high levels of troponin. However high cardiac troponin levels could be observed in massive pulmonary embolism and cardiac troponins could help to determine right ventricular dysfunction and to predict early mortality.

\section{Funding}

This study is supported by Gazi University Research Fund, Ankara, Turkey.

\section{References}

1. Wells PS, Rodger M (2003) Diagnosis of pulmonary embolism: when is imaging needed? Clin Chest Med 24: 13-28.

2. Giannitsis E, Müller-Bardorff M, Kurowski V, Weidtmann B, Wiegand U, et al. (2000) Independent prognostic value of cardiac troponin $T$ in patients with confirmed pulmonary embolism. Circulation 102: 211-217.

3. Tapson VF (2003) Diagnosing and managing acute pulmonary embolism: Role of cardiac troponins. Am Heart J 145: 751-753.

4. Becattini C, Agnelli G (2001) Risk factors for adverse short-term outcome in patients with pulmonary embolism. Thromb Res 103: V239-244

5. Mehta NJ, Jani K, Khan IA (2003) Clinical usefulness and prognostic value of elevated cardiac troponin I levels in acute pulmonary embolism. Am Heart $J$ 145: 821-825.

6. Meyer T, Binder L, Hruska N, Luthe H, Buchwald AB (2000) Cardiac troponin I elevation in acute pulmonary embolism is associated with right ventricular dysfunction. J Am Coll Cardiol 36: 1632-1636.

7. Adams JE 3rd, Bodor GS, Dávila-Román VG, Delmez JA, Apple FS, et al. (1993) Cardiac troponin I. A marker with high specificity for cardiac injury. Circulation 88: 101-106.

8. Brooks H, Kirk ES, Vokonas PS, Urschel CW, Sonnenblick EH (1971) Performance of the right ventricle under stress: relation to right coronary flow. J Clin Invest 50: 2176-2183.

9. Coma-Canella I, Gamallo C, Martinez Onsurbe P, Lopez-Sendon J (1988) Acute right ventricular infarction secondary to massive pulmonary embolism. Eur Heart J 9: 534-540.

10. Douketis JD, Crowther MA, Stanton EB, Ginsberg JS (2002) Elevated cardiac troponin levels in patients with submassive pulmonary embolism. Arch Intern Med 162: 79-81.

11. Polanczyk C, Lee T, Cook F, Walls R, Wybenga D, et al. (1998) Cardiac troponin
I as a predictor of major cardiac events in emergency department patients with acute chest pain. J Am Coll Cardiol 32: 8-14

12. Hamm CW, Goldmann BU, Heeschen C, Kreymann G, Berger J, et al. (1997) Emergency room triage of patients with acute chest pain by means of rapid testing for cardiac troponin T or troponin I. N Engl J Med 337: 1648-1653.

13. Pruszczyk P, Bochowicz A, Torbicki A, Szulc M, Kurzyna M, et al. (2000) Chest 123: 1947-1952.

14. Tapson VF, Carroll BA, Davidson BL, Elliott CG, Fedullo PF, et al. (1999) The diagnostic approach to acute venous thromboembolism. Clinical practice guideline. American Thoracic Society. Am J Respir Crit Care Med 160: 1043-1066.

15. Baile EM, King GG, Müller NL, D'Yachkova Y, Coche EE, et al. (2000) Spira computed tomography is comparable to angiography for the diagnosis of pulmonary embolism. Am J Respir Crit Care Med 161: 1010-1015

16. Grenier PA, Beigelman C (1998) Spiral computed tomographic scanning and magnetic resonance angiography for the diagnosis of pulmonary embolism Thorax 53 Suppl 2: S25-31.

17. [No authors listed] (1990) Value of the ventilation/perfusion scan in acute pulmonary embolism. Results of the prospective investigation of pulmonary embolism diagnosis (PIOPED). The PIOPED Investigators. JAMA 263: 2753 2759 .

18. Bartlett JG, Dowell SF, Mandell LA, File Jr TM, Musher DM, et al. (2000) Practice guidelines for the management of community-acquired pneumonia in adults. Infectious Diseases Society of America. Clin Infect Dis 31: 347-382.

19. Global initiative for asthma (GINA) Global strategy for Asthma management and prevention. NHLBI/WHO workshop report. National Institute of Health. National heart, Lung and Blood institute. Revised 2002 NIH Publication No: 02-5639.

20. Ammann P, Pfisterer M, Fehr T, Rickli H (2004) Raised cardiac troponins. BM 328: 1028-1029.

21. Fox KA, Birkhead J, Wilcox R, Knight C, British Cardiac Society Working Group, et al. (2004) British Cardiac Society Working Group on the definition of myocardial infarction. Heart 90: 603-609.

22. Goldhaber SZ, Visani L, De Rosa M (1999) Acute pulmonary embolism: clinica outcomes in the International Cooperative Pulmonary Embolism Registry (ICOPER) Lancet 353: 1386-1389.

23. Goldhaber SZ (1995) Treatment of acute pulmonary embolism. In: Braunwald E, Goldhaber SZ, eds. Atlas of Heart Disease. Cardiopulmonary Diseases and Cardiac Tumors Philadelphia Pa: Current Medicine.

24. La Vecchia L, Ottani F, Favero L, Spadaro GL, Rubboli A, et al. (2004) Increased cardiac troponin I on admission predicts in-hospital mortality in acute pulmonary embolism. Heart 90: 633-637.

25. National Committee for Clinical Laboratory Standarts. Protection of laboratory workers from instrument biohazards and infectious disease transmitted by blood, body fluids, and tissue: Approved guideline. NCCLS Document M29-A.

26. Gunnewiek JM, Van Der Hoeven JG (2004) Cardiac troponin elevations among critically ill patients. Curr Opin Crit Care 10: 342-346.

27. Müller-Bardorff M, Weidtmann B, Giannitsis E, Kurowski V, Katus HA (2002) Release kinetics of cardiac troponin $T$ in survivors of confirmed severe pulmonary embolism. Clin Chem 48: 673-675.

28. Adams JE 3rd, Siegel BA, Goldstein JA, Jaffe AS (1992) Elevations of CK MB following pulmonary embolism. A manifestation of occult right ventricular infarction. Chest 101: 1203-1206.

29. Kucher N, Walpoth N, Wustmann K, Noveanu M, Gertsch M, et al. (2003) QR in V1- an ECG sign associated with right ventricular strain and adverse clinical outcome in pulmonary embolism. Eur Heart J 24: 1113-1119.

30. Kucher N, Goldhaber SZ (2003) Cardiac biomarkers for risk stratification of patients with acute pulmonary embolism. Circulation 108: 2191-2194.

31. Meyer G, Roy PM, Sors H, Sanchez O (2003) Laboratory tests in the diagnosis of pulmonary embolism. Respiration 70: 125-132.

32. Moammar MQ, Ali MI, Mahmood NA, DeBari VA, Khan MA (2010) Cardiac troponin I levels and alveolar-arterial oxygen gradient in patients with community-acquired pneumonia. Heart Lung Circ 19: 90-92.

33. Weinberg I, Cukierman T, Chajek-Shaul T (2002) Troponin T elevation in loba lung disease. Postgrad Med J 78: 244-245. 
Citation: Demir N, Ekim N, Oguzulgen IK, Bukan N (2012) The Value of Cardiac Troponins in Diagnosis and Differential Diagnosis of Pulmonary Embolism. J Pulmon Resp Med 2:134. doi:10.4172/2161-105X.1000134

34. Kucher N, Wallmann D, Carone A, Windecker S, Meier B, et al. (2003) Incremental prognostic value of troponin I and echocardiography in patients with acute pulmonary embolism. Eur Heart J 24: 1651-1656

35. Konstantinides S, Geibel A, Olschewski M, Kasper W, Hruska N, et al. (2002) Importance of cardiac troponins I and $\mathrm{T}$ in risk stratification of patients with acute pulmonary embolism. Circulation 106: 1263-1268.

36. Grifoni S, Olivotto I, Cecchini P, Pieralli F, Camaiti A, et al. (2000) Short-term clinical outcome of patients with acute pulmonary embolism, normal blood pressure, and echocardiographic right ventricular dysfunction. Circulation 101 2817-2822.

37. Kasper W, Konstantinides S, Geibel A, Tiede N, Krause T, et al. (1997) Prognostic significance of right ventricular afterload stress detected by echocardiography in patients with clinically suspected pulmonary embolism. Heart 77: 346-349.

38. Janata K, Holzer M, Laggner AN, Müllner M (2003) Cardiac troponin T in the severity assessment of patients with pulmonary embolism: cohort study. BMJ 326: $312-313$

39. Kline JA, Johns KL, Colucciello SA, Israel EG (2000) New diagnostic tests for pulmonary embolism. Ann Emerg Med 36: 280-281.

40. Kutinsky I, Blakley S, Roche V (1999) Normal D-dimer levels in patients with pulmonary embolism. Arch Intern Med 159: 1569-1572.

41. De Monyé W, Sanson BJ, Mac Gillavry MR, Pattynama PM, Büller HR, et al (2002) Embolus location affects the sensitivity of a rapid quantitative D-dimer assay in the diagnosis of pulmonary embolism. Am J Respir Crit Care Med 165: 345-348.

42. Wells PS, Anderson DR, Rodger M, Stiell I, Dreyer JF, et al. (2001) Excluding pulmonary embolism at the bedside without diagnostic imaging: management of patients with suspected pulmonary embolism presenting to the emergency department by using a simple clinical model and d-dimer. Ann Intern Med 135 : 98-107. 